\title{
Dermoscopy of Eumycotic Mycetoma: A Case Report
}

\author{
Balachandra S. Ankad ${ }^{1}$, R. Manjula ${ }^{1}$, Trilokraj Tejasvi ${ }^{2}$, Balakrishna P. Nikam ${ }^{3}$
}

\begin{abstract}
1 Department of Dermatology, S. Nijalingappa Medical College, Karnataka, India 2 Michigan Medicine Dermatology, University of Michigan, Ann Arbor, MI, USA 3 Krishna Institute of Medical Sciences, Karad, Maharashtra, India
\end{abstract}

Key words: dermoscopy, eumycotic mycetoma, yellow globules, patterns

Citation: Ankad BS, Manjula R, Tejasvi T, Nikam BP. Dermoscopy of eumycotic mycetoma: a case report. Dermatol Pract Concept. 2019;9(4):297-299. DOI: https://doi.org/10.5826/dpc.0904a10

Accepted: April 1, 2019; Published: October 31, 2019

Copyright: $@ 2019$ Ankad et al. This is an open-access article distributed under the terms of the Creative Commons Attribution License, which permits unrestricted use, distribution, and reproduction in any medium, provided the original author and source are credited.

Funding: None.

Competing interests: The authors have no conflicts of interest to disclose.

Authorship: All authors have contributed significantly to this publication.

Corresponding author: Balachandra S. Ankad, MD, Department of Dermatology, S. Nijalingappa Medical College, Near APMC, Navanagar, Bagalkot 587103, Karnataka, India. Email: drbsankad@gmail.com

\section{Introduction}

Eumycotic mycetoma is a localized suppurative, granulomatous infection of subcutaneous tissue, which is characterized by the triad of painless mass, discharging sinuses, and grains/ granules. It develops after a penetrating injury causing inoculation of the organism that eventually results in a local disease, followed by spread of the infection to the surrounding soft tissues and osseous structures [1]. Dermoscopy has become a very important noninvasive tool to assist in the diagnosis of many infectious diseases and infestations. There are few reports demonstrating the utility of dermoscopy in the diagnosis of subcutaneous fungal infections such as chromoblastomycosis [2] and eumycotic mycetoma [1]. Here we report the dermoscopic patterns of a case of eumycotic mycetoma caused by Madurella species in a patient with skin type 5 .

\section{Case Presentation}

A 46-year-old man presented with a 2-year history of skin lesions on the left wrist that developed after a thorn prick. A
Figure 1. Clinical image of eumycotic mycetoma showing slightly indurated mass with discharging sinuses on the wrist (A) before and (B) after treatment. [Copyright: (C2019 Ankad et al.]
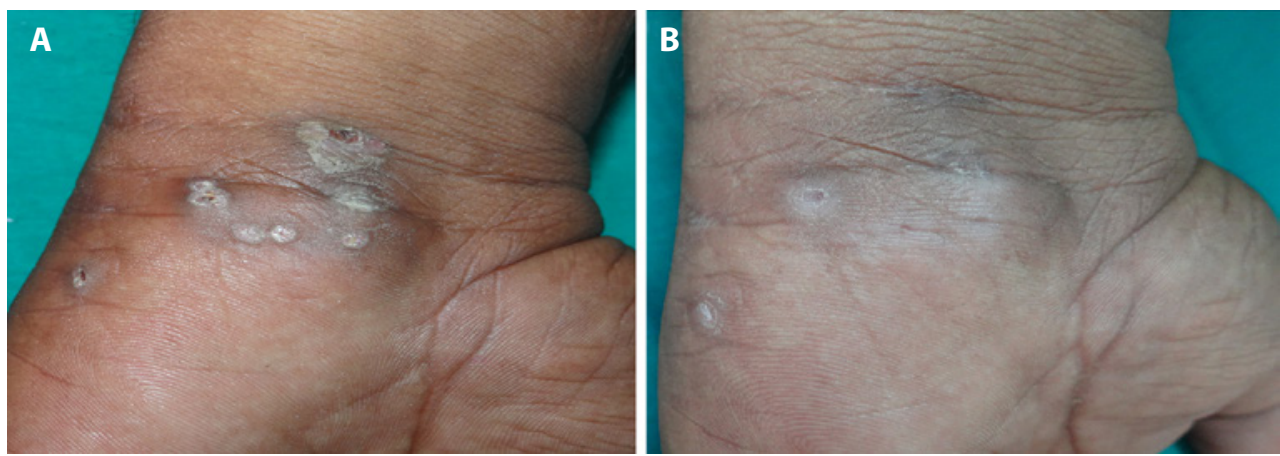

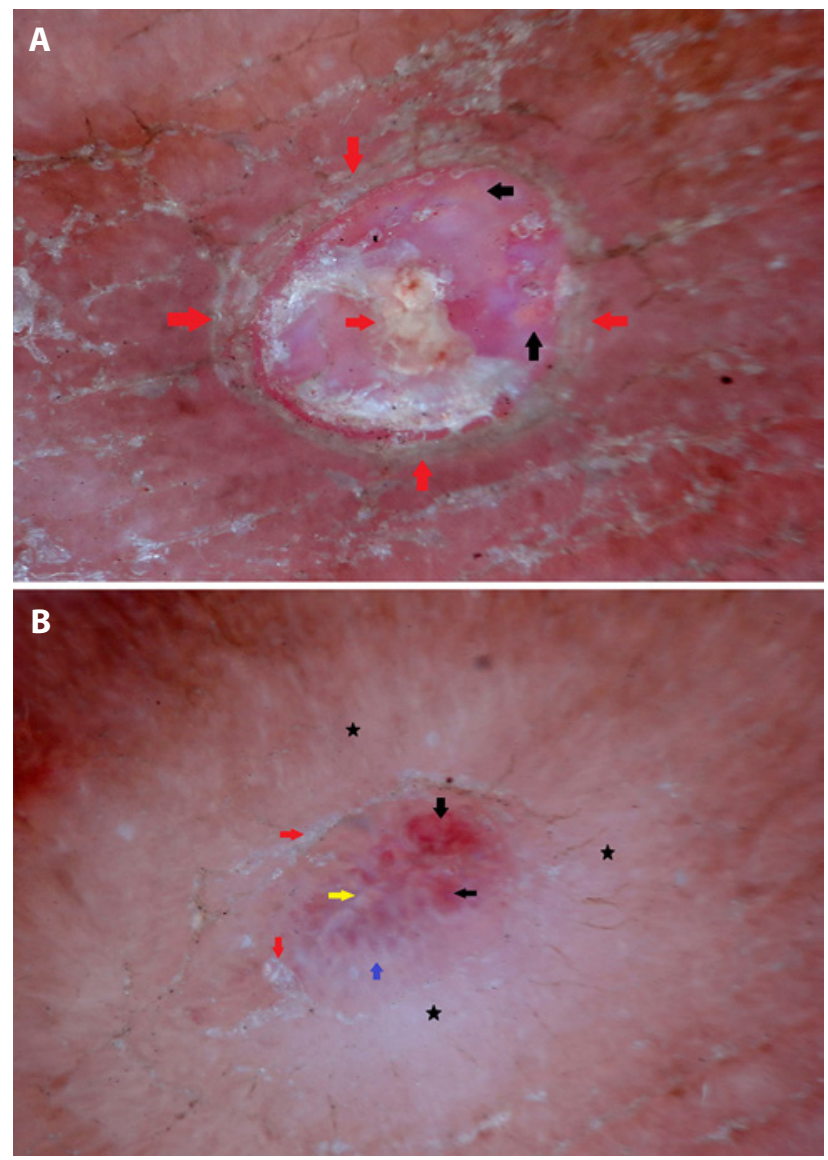

Figure 2. Dermoscopy of eumycotic mycetoma; lesion 1: (A) Before treatment, yellow globules (black arrows) and white superficial scales (red arrows) are seen. (B) After treatment, yellow globules (yellow arrow), white superficial scales (red arrows), white globules (blue arrow), and red structureless areas (black arrows) are observed. Note the reduction of structures except whitish structureless areas (black stars). [Copyright: @2019 Ankad et al.]

surgeon had previously excised the thorn. The patient reported extrusion of black particles from the lesion initially. Examination revealed a mildly indurated mass with multiple discharging sinuses (Figure 1A). Dermoscopic examination, using DermLite 3 with $\times 10$ magnification in contact polarized mode, showed yellow globules, white superficial scales, telangiectasia and dotted vessels, blood spots, and whitish structureless areas (Figures 2A and 3A). Histopathology was consistent with eumycotic mycetoma with demonstration of granulomatous reaction and granules in mid dermis (Figure 4). Madurella grisea species was isolated on culture. The patient was treated with itraconazole $100 \mathrm{mg}$ twice daily for 2 months, resulting in complete resolution of skin lesions (Figure 1B). After the therapy, dermoscopic assessment revealed a reduction in yellow globules, white superficial scales, and dotted vessels, while
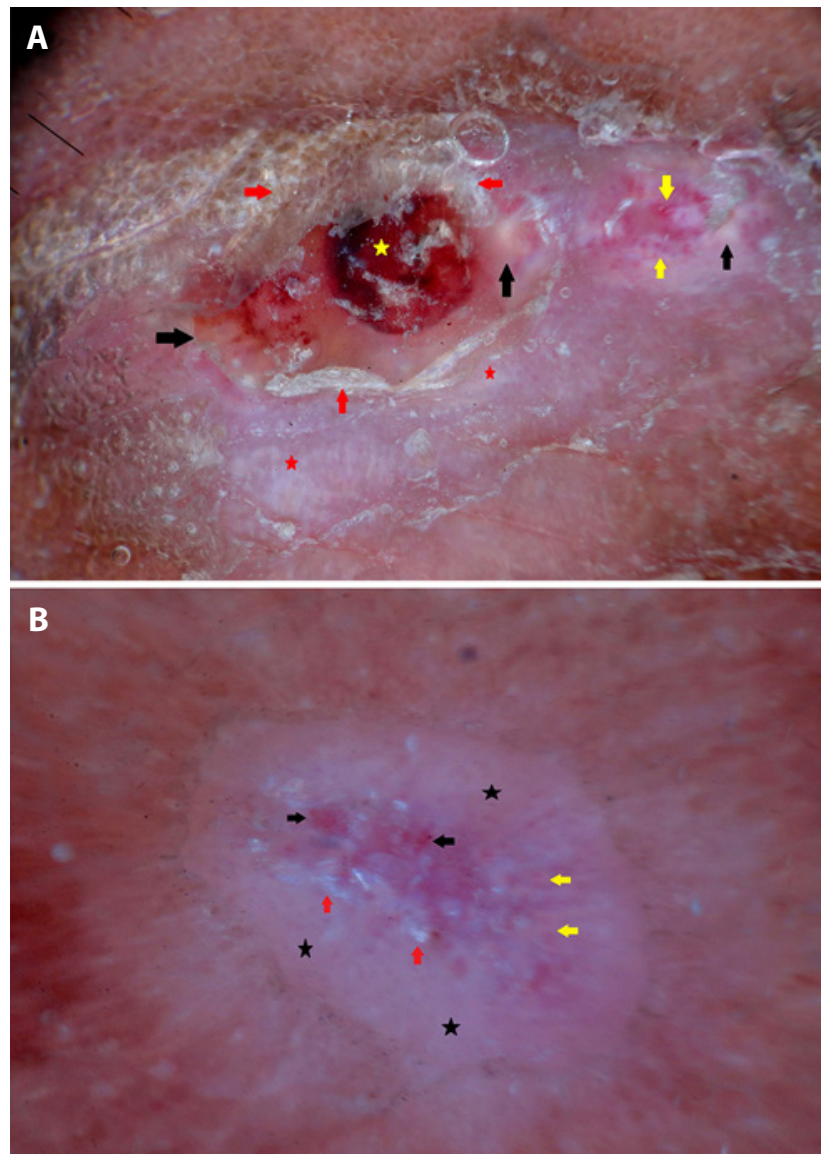

Figure 3. Dermoscopy of eumycotic mycetoma; lesion 2: (A) Before treatment, yellow globules (black arrows), whitish structureless areas (red stars), telangiectasia and dotted vessels (yellow arrows), white superficial scales (red arrows), and blood spots (yellow star) are seen. (B) After treatment, reduction in yellow globules (yellow arrows), white superficial scales (red arrows), and dotted vessels (black arrows) are observed. Note the prominent whitish structureless areas (black stars) after treatment. [Copyright: (O)2019 Ankad et al.]

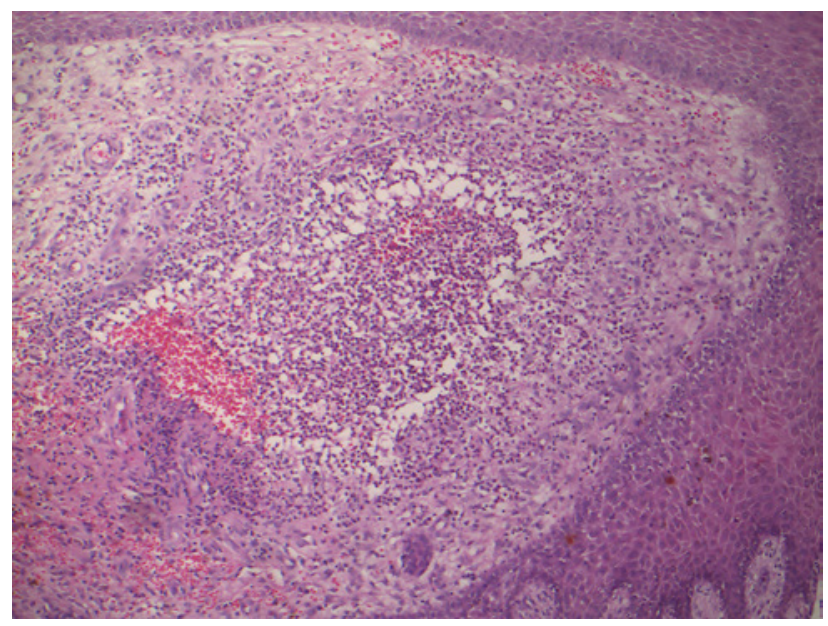

Figure 4. Histopathology of eumycotic mycetoma shows suppurative granuloma composed of neutrophils in the dermis $(\mathrm{H} \& \mathrm{E}, \times 10)$. [Copyright: (2019 Ankad et al.] 
whitish structureless areas were more pronounced compared with the initial picture (Figures $2 \mathrm{~B}$ and $3 \mathrm{~B}$ ).

\section{Discussion}

From a dermoscopic-pathological correlation point of view, yellow globules detected in our case could correspond to dermal granulomas caused by Madurella. Generally, granuloma demonstrates orange-yellow globules. Here, yellow color probably is due to granulomatous reaction with many neutrophils. Whitish structureless areas and white superficial scales were other unspecific dermoscopic findings, which represent dermal fibrosis and hyperkeratosis, respectively. Finally, blood spots represented dried blood.

In a previous report, dermoscopy of eumycetoma showed white and yellow structures, which were similar to the present case [1]. In addition, white superficial scales and telangiectasia, blood spots, and dotted vessels were seen in our instance. In chromoblastomycosis, dermoscopy shows yellow globules, black dots, crusting, and white areas, which are [2] similar to mycetoma patterns, so the only difference from eumycetoma is the detection of black dots.

Interestingly, many of the dermoscopic findings (yellow globules, telangiectasias, blood spots, and white scales) were reduced significantly after the therapy, thereby emphasizing that their resolution can be helpful when monitoring treatment response.

\section{Conclusions}

Besides poorly specific findings (white structureless areas, telangiectasias, blood spots, and white scales), eumycotic mycetoma due to Madurella species may feature yellow globules. These structures may be related to the granulomatous reaction, and their detection might be of aid, along with clinical and anamnestic data, in suspecting such a condition and guiding the clinician in taking samples for microbiological analysis in order to reach a definitive diagnosis. Since this is a single case based on observation, further studies involving larger samples are recommended to elucidate and validate our findings.

\section{References}

1. Reis LM, Lima BZ, Zillo Fda C, Rezende CM, Fabricio LH, Pinto CA. Dermoscopy assisting the diagnosis of mycetoma: case report and literature review. An Bras Dermatol. 2014;89(5):832-833.

2. Subhadarshani S, Yadav D. Dermoscopy of chromoblastomycosis. Dermatol Pract Concept. 2017;7(4):23-24. 